J. Dairy Sci. 95:5495-5509

http://dx.doi.org/10.3168/jds.2011-4756

(C) American Dairy Science Association ${ }^{\circledR}$, 2012. Open access under CC BY-NC-ND license.

\title{
Safety of a probiotic cheese containing Lactobacillus plantarum Tensia according to a variety of health indices in different age groups
}

\author{
E. Songisepp, ${ }^{* 1}$ P. Hütt, ${ }^{\star} \dagger$ M. Rätsep, ${ }^{*}$ E. Shkut, ${ }^{*}$ S. Kõljalg, $†$ K. Truusalu, $†$ J. Stsepetova, $\dagger$ I. Smidt, $\dagger$ \\ H. Kolk, $\ddagger$ M. Zagura, $\S$ and M. Mikelsaar† \\ *Bio-Competence Centre of Healthy Dairy Products LLC, Kreutzwaldi Str. 1, 51014, Tartu, Estonia \\ †Department of Microbiology, University of Tartu, Ravila Str. 19, Tartu 50411, Estonia \\ ‡Department of Traumatology and Orthopedics, University of Tartu, L. Puusepa Str. 8, Tartu 51014, Estonia \\ §Tartu University Clinics, Department of Cardiology, L. Puusepa Str. 8, Tartu 51014, Estonia
}

\section{ABSTRACT}

Safety of the probiotic Lactobacillus plantarum strain Tensia (DSM 21380) was tested in vitro, in semihard Edam-type cheese, in an animal model and after consumption of the probiotic cheese in double-blind randomized placebo-controlled human intervention studies with different age groups. The susceptibility of L. plantarum Tensia to 8 antibiotics, and the presence of tetracycline (tet $\mathrm{M}, \mathrm{S}, \mathrm{O}, \mathrm{K}, \mathrm{L}$ ) genes and class 1 integron was assessed by applying epsilometer-test and PCR-based methods. Production of biogenic amines by the probiotic strain in decarboxylation medium containing $1 \%$ of L-histidine, L-glutamine, L-ornithine, L-arginine, or L-lysine and in cheese was tested by gas chromatography. The biosafety of $L$. plantarum Tensia was evaluated on National Institutes of Health-line mice fed cheese containing Tensia at a concentration of $9.6 \mathrm{log} \mathrm{cfu} / \mathrm{g}$ for 30 consecutive days. In human intervention trials in adults and the elderly, the effects of different doses of Edam-type cheese and the probiotic bacterium on BW, gut functionality indices, and host metabolism were evaluated. The strain L. plantarum Tensia was susceptible to all tested antibiotics and did not possess the tetracycline resistance-determining genes $\operatorname{tet}(\mathrm{L}), \operatorname{tet}(\mathrm{S})$ and $\operatorname{tet}(\mathrm{O})$, nor did it contain the integron (Int1) gene. However, the strain was tet $(\mathrm{K})$ and tet $(\mathrm{M})$ positive. Lactobacillus plantarum Tensia did not produce potentially harmful biogenic amines, such as histamine or cadaverine. The amount of tyramine produced in the cheese environment during ripening and after 15 wk of storage was below the clinically significant content. In the animal model, no translocation of the administered strain or other microbes into the blood or organs of mice was detected. No harmful effect was observed on body mass index, inflammatory

Received July 22, 2011.

Accepted May 22, 2012.

${ }^{1}$ Corresponding author: esongisepp@gmail.com markers, or serum lipidograms during human intervention trials with different age groups at a daily dose of 10.3 or $8.17 \mathrm{log} \mathrm{cfu} / \mathrm{serving}$ for $3 \mathrm{wk}$. No negative effect on gastrointestinal welfare was observed, but the consumption of $100 \mathrm{~g} / \mathrm{d}$ for 3 wk caused hard stools from the second week of the trial. The content of total lactobacilli increased in feces, and the presence of the ingested probiotic strain was confirmed after the consumption of cheese. Thus, L. plantarum strain Tensia is suitable for generally recognized as safe (GRAS) and qualified presumption of safety (QPS) criteria because it did not have any undesirable characteristics. The regular semihard Edam-type cheese (fat content of $26 \%$ ) with the probiotic additive at a daily dose of $50 \mathrm{~g}$ or in excess $(100 \mathrm{~g})$ and with a probiotic daily dose of $10 \log$ cfu for 3 wk was safe.

Key words: Edam-type cheese, Lactobacillus plantarum, probiotic, safety

\section{INTRODUCTION}

To date, the close link between intestinal microbiota, nutrition, and human metabolism has increased interest in functional food applications (e.g., pre- and probiotic products) for health promotion in different age groups. A variety of probiotic dairy products, including cheeses with particular functional properties, is available on the market worldwide (Gomes et al., 1995; Gardiner et al., 1998; Songisepp et al., 2004; Ross et al., 2005; Ibrahim et al., 2010). Probiotics are defined as live microorganisms, which, when consumed in appropriate amounts in the food, confer a health benefit on the host (FAO/ WHO, 2002). Their identity, safety, and health claims have attracted a large amount of attention from different public and regulatory organizations.

The putative probiotic strain should be accurately characterized and identified (Vankerckhoven et al., 2008), with its functional properties and the ability for temporal colonization (bile, gastric acid tolerance, and adhesive properties) confirmed in vitro (Saarela et 
al., 2000; Kõll et al., 2010). Recent recommendations include the absence of hemolytic activity and transferable antibiotic resistance of the selected Lactobacillus strain, whereas the safety should be proven in animal models (FAO/WHO, 2002; Vesterlund et al., 2007; Kõll et al., 2010). Next, pilot clinical trials on healthy volunteers are needed, to exclude probiotic administration having adverse effects on gut health and biochemical and cellular indices of the blood, reflecting the proper functions of human organs (Reid, 2005; Mercenier et al., 2008; Rijkers et al., 2010). Further, only after these procedures should the expression of the functional properties of the strain - either by improving some physiological functions (e.g., antimicrobial, metabolic, immunogenic, antioxidative) of the host or by reducing the risk of some diseases after consumption of the probiotic product-be tested in large groups of volunteers. Several studies have found an inverse relationship between the intake of low-fat dairy products and the incidence of cardiovascular diseases (CVD), preclinical atherosclerosis, and cardiovascular risk factors in middle-age and older age persons (Djoussé et al., 2006; Engberink et al., 2009; Levitan et al., 2009; Toledo et al., 2009). However, few safety assessments have been directed toward the control of biomarkers of host basic metabolism, particularly carbohydrates, lipids, and AA turnover, after administration of a dairy probiotic. Furthermore, it has not been elucidated how the addition of a probiotic strain to a full-fat dairy product affects gut functionality indices of the host.

Here, we report on clinical probiotic food intervention trials in adults and the elderly in which the tolerability and safety of a cheese containing a probiotic Lactobacillus plantarum strain was tested according to multiple health markers. In particular, a regular Edamtype cheese containing the probiotic L. plantarum strain Tensia (DSM 21380) was clinically evaluated in healthy Estonian individuals of 2 different age groups (adults and the elderly). The effects of different doses of cheese and probiotic bacteria on gut health indices; BW; functionality markers of the liver and kidneys; and hematological (hemoglobin, erythrocytes, and lymphocytes), metabolic (plasma glucose, glycohemoglobin, and lipids), and inflammatory indices [white blood cell count, high-sensitivity C-reactive protein (hs-CRP)] were evaluated.

\section{MATERIALS AND METHODS}

\section{Probiotic Strain}

A novel probiotic Lactobacillus strain was previously isolated from a fecal sample of a healthy child (Mikelsaar et al., 2002; Annuk et al., 2003). The mo- lecular identification of the strain as L. plantarum was confirmed by internal-transcribed spacer PCR and $16 \mathrm{~S}$ rRNA sequencing. The functional properties and health effects of the strain have been described elsewhere (Songisepp et al., 2009). The strain L. plantarum Tensia was deposited in Deutsche Sammlung von Mikroorganismen und Zellkulturen GmbH (Braunschweig, Germany) under the registration number DSM 21380 on April 16, 2008.

\section{Hemolytic Activity}

A single line of lactobacilli culture [grown in de Man, Rogosa, Sharpe broth (MRS; Oxoid, Basingstoke, UK) for $48 \mathrm{~h}$ ] was streaked onto blood agar plates containing either human or sheep blood. Hemolysis of L. plantarum Tensia was evaluated after 24 and $48 \mathrm{~h}$ of incubation in aerobic, microaerobic $\left(10 \% \mathrm{CO}_{2}\right)$, and anaerobic $(90 \%$ $\left.\mathrm{N}_{2}, 5 \% \mathrm{CO}_{2}, 5 \% \mathrm{H}\right)$ environments. One Staphylococcus aureus strain (ATCC 25923) and 1 Streptococcus pyogenes strain (ATCC 19615) were used as positive controls.

\section{Antibacterial Susceptibility Testing}

The susceptibility to kanamycin, ampicillin, gentamicin, streptomycin, erythromycin, clindamycin, tetracycline, chloramphenicol, and quinupristin/dalfopristin was assessed according to European Union Commission recommendations for probiotic safety (EFSA, 2008). The MIC of antibiotics to L. plantarum Tensia was determined by applying an epsilometer-test strip (AB Biodisk, Piscataway, NJ; Mayrhofer et al., 2008) on an inoculated Lactic Acid Bacteria Susceptibility Test Medium containing Iso-Sensitest agar $(90 \%, \mathrm{vol} / \mathrm{vol})$ and MRS agar (10\%, vol/vol), pH 6.7 (both from Oxoid; Klare et al., 2005). The results were read after $24 \mathrm{~h}$ of incubation at $35^{\circ} \mathrm{C}$ in a microaerobic environment (CampyPak Plus, BD, Franklin Lakes, NJ).

\section{Presence of tet and Int1 Genes Analyzed by PCR}

Total DNA of L. plantarum Tensia was extracted using a QIAamp DNA Mini Kit (Qiagen GmbH, Hilden, Germany) following the manufacturer's protocol. Polymerase chain reactions were carried out in a $50-\mu \mathrm{L}$ volume containing $10 \times \mathrm{PCR}$ buffer, $2.5 \mathrm{mM} \mathrm{MgCl}, 2.5$ $\mathrm{mM}$ deoxynucleotide $5^{\prime}$-triphosphates, $20 \mathrm{pmol}$ of each primer (Table 1), $2.5 \mathrm{U}$ of Taq polymerase (Fermentas, Vilnius, Lithuania), and $2 \mu \mathrm{g}$ of template DNA. For detection of the possible presence of tet genes encoding ribosomal protection proteins, the degenerate primers DI and DII were used. If positive, additional PCR assays were performed with primers specific for the tet(M), 
Table 1. Primers for PCR detection of the tet and Int genes ${ }^{1}$

\begin{tabular}{|c|c|c|}
\hline Primer pair & $\begin{array}{l}\text { Gene(s) } \\
\text { targeted }\end{array}$ & Sequence \\
\hline DI & $\mathrm{RPP}$ & 5'-GAYACNCCNGGNCAYRTNGAYTT-3' \\
\hline DII & $\mathrm{RPP}$ & 5'-GCCCARWANGGRTTNGGNGGNACYTC-3' \\
\hline DI & $\operatorname{tet}(\mathrm{M})$ & 5'-GAYACNCCNGGNCAYRTNGAYTT-3' \\
\hline TetrM-R & $\operatorname{tet}(\mathrm{M})$ & 5'-CACCGAGCAGGGATTTCTCCAC-3' \\
\hline TetO-f & $\operatorname{tet}(\mathrm{O})$ & 5'-AATGAAGATTCCGACAATTT-3' \\
\hline TetO-r & $\operatorname{tet}(\mathrm{O})$ & 5'-CTCATGCGTTGTAGTATTCCA-3' \\
\hline TetS-f & tet $(\mathrm{S})$ & 5'-ATCAAGATATTAAGGAC-3' \\
\hline TetS-r & tet $(\mathrm{S})$ & 5'-TTCTCTATGTGGTAATC-3' \\
\hline TetK-f & tet $(\mathrm{K})$ & 5'-TTATGGTGGTTGTAGCTAGAAA-3' \\
\hline TetK-r & $\operatorname{tet}(\mathrm{K})$ & 5'- AAAGGGTTAGAAACTCTTGAAA-3' \\
\hline TetL-f & tet $(\mathrm{L})$ & 5'-GTMGTTGCGCGCTATATTCC-3' \\
\hline TetL-R & $\operatorname{tet}(\mathrm{L})$ & 5'-GTGAAMGRWGCCCACCTAA-3' \\
\hline $5^{\prime} \mathrm{CS}$ & Int1 & 5'-GGCATCCAAGCAGCAAG-3' \\
\hline $3^{\prime} \mathrm{CS}$ & Int1 & 5'-AAGCAGACTTGACCTGA-3' \\
\hline
\end{tabular}

${ }^{1} \mathrm{DI}$ and $\mathrm{DII}=$ degenerate primers; $\mathrm{RPP}=$ ribosomal protection protein; $\mathrm{CS}=$ conserved segment; tet $=$ tetracycline; Int $=$ integron.

tet $(\mathrm{O})$, and tet $(\mathrm{S})$ genes. Next, L. plantarum Tensia was tested for the presence of the tetracycline efflux genes tet $(\mathrm{K})$ and tet(L) (Gevers et al., 2003a,b).

For detection of the possible presence of integron, a class 1 integrase-specific fragment of the Int1 gene was used (Lévesque et al., 1995). Polymerase chain reaction amplicons for tet genes were performed in an Eppendorf PCR System (Eppendorf AG, Hamburg, Germany) with the following programs: initial denaturation at $94^{\circ} \mathrm{C}$ for $5 \mathrm{~min}$; 35 cycles of $94^{\circ} \mathrm{C}$ for $1 \mathrm{~min}$, annealing temperature [ribosomal protection protein gene at $45^{\circ} \mathrm{C} ; \operatorname{tet}(\mathrm{M}), \operatorname{tet}(\mathrm{K}), \operatorname{tet}(\mathrm{L}), \operatorname{tet}(\mathrm{S})$, and $\operatorname{tet}(\mathrm{O})$ at $\left.55^{\circ} \mathrm{C}\right]$ for $1 \mathrm{~min}$, and $72^{\circ} \mathrm{C}$ for $2 \mathrm{~min}$; and a final extension step at $72^{\circ} \mathrm{C}$ for $10 \mathrm{~min}$. Amplification specifications for integrase Int 1 were as follows: $94^{\circ} \mathrm{C}$ for $5 \mathrm{~min}$, followed by 25 cycles of $94^{\circ} \mathrm{C}$ for $30 \mathrm{~s}, 55^{\circ} \mathrm{C}$ for $30 \mathrm{~s}$, and $72^{\circ} \mathrm{C}$ for $30 \mathrm{~s}$, and a final extension at $72^{\circ} \mathrm{C}$ for $7 \mathrm{~min}$. Amplicons were electrophoresed on 1.5\% agarose gel, and a 1-kb ladder (Fermentas) was used as a molecular size marker.

\section{Production of Biogenic Amines}

In Decarboxylation Medium. Lactobacillus plantarum Tensia strain DSM 21379 and Escherichia coli ATCC 700336 were used as positive controls. A $0.5-\mathrm{mL}$ (9-log cfu/mL) amount of the microbial suspension was further seeded into $4.5 \mathrm{~mL}$ of the decarboxylase broth (Difco Decarboxylase Base Moeller, BD) containing $1 \%$ of L-histidine, L-glutamine, L-ornithine, L-arginine, or L-lysine and incubated at $37^{\circ} \mathrm{C}$ for $4 \mathrm{~d}$. A $200-\mu \mathrm{L}$ volume of reaction medium was derivatized for gas chromatography analysis by a modification of the method of Nakovich (2003). For detection of biogenic amines (BA), gas chromatography analyses were carried out using an HP 6890 Series GC System with an
HP-5 19091J-413 capillary column $(30 \mathrm{~m} \times 0.32 \mathrm{~mm}$; $0.25 \mu \mathrm{m}$ i.d.; Agilent, Santa Clara, CA). The column temperature program was $160^{\circ} \mathrm{C}$ and was held for $1 \mathrm{~min}$ and increased at $20^{\circ} \mathrm{C} / \mathrm{min}$ to $280^{\circ} \mathrm{C}$ for $15 \mathrm{~min}$; the flame-ionization detector temperature was $300^{\circ} \mathrm{C}$.

In Milk. Fat-free milk was inoculated with $10^{7} \mathrm{cfu} /$ $\mathrm{mL}$ of the Tensia strain and incubated at $37^{\circ} \mathrm{C}$ for $40 \mathrm{~d}$. Samples were taken at the beginning of the trial and on d 12 and 40 from the inoculation.

\section{Cheese Containing L. plantarum Tensia}

Gas chromatography profiles of propyl chloroformate amines extracted from cheese samples were detected. The cheese samples were extracted as follows: $20 \mathrm{~mL}$ of $50 \%$ methanol solution was added to $10 \mathrm{~g}$ of cheese and incubated at $45^{\circ} \mathrm{C}$ for $1 \mathrm{~h}$, cooled to $30^{\circ} \mathrm{C}$, and centrifuged. A $200-\mu \mathrm{L}$ volume of the upper layer was derivatized for gas chromatography and analyzed by a modification of the method of Nakovich (2003).

\section{Cheese Preparation}

The probiotic cheese containing L. plantarum Tensia was developed at the Dairy Cooperative E-Piim, (Põltsamaa, Estonia). Shortly thereafter, semihard Edamtype cheeses were prepared from cow's milk with 0.8 to $1 \%$ of $\mathrm{C} 92$ precultured cheese starter (CSK Food Enrichment, Leeuwarden, the Netherlands). Two different cheeses were prepared: regular Edam-type cheese as the control, and Edam-type cheese containing the L. plantarum strain Tensia as an adjunct starter. The total counts of live L. plantarum Tensia per gram of cheese are presented in Table 2. Before renneting, $L$. plantarum Tensia was added to the pasteurized milk together with the starter. The milk was renneted (25 min 
Table 2. Designs of intervention studies with healthy adults and the elderly

\begin{tabular}{|c|c|c|c|}
\hline Variable & \multicolumn{2}{|c|}{$\mathrm{DBPC}^{1}$ intervention study } & $\begin{array}{l}\text { Open-label intervention study } \\
\text { Study } 3\end{array}$ \\
\hline Study acronym & TE 1 & ELD & TE 5 \\
\hline Duration of the trial (wk) & 8 & 8 & 3 \\
\hline Duration of the test period (wk) & 3 & 3 & 3 \\
\hline Duration of washout (wk) & 2 & 2 & - \\
\hline Daily dose of probiotic $\left(\log _{10} \mathrm{cfu}\right)$ & 10.4 & 8.17 & 10.3 \\
\hline Daily dose of cheese $(\mathrm{g})$ & 50 & 50 & 100 \\
\hline Cheese age (wk) & 12 to 15 & 13 to 16 & 12 to 15 \\
\hline Fat intake with cheese $(\mathrm{g} / \mathrm{d})$ & 13 & 13 & 26 \\
\hline Saturated fat intake with cheese $(\mathrm{g} / \mathrm{d})$ & 8 & 8 & 16 \\
\hline Cholesterol intake with cheese (mg/d) & 45 & 45 & 89 \\
\hline
\end{tabular}

${ }^{1} \mathrm{DBPC}=$ double-blind placebo-controlled.

${ }^{2}$ ISRCTN $=$ International Standard Randomized Controlled Trial Number.

at $\left.32^{\circ} \mathrm{C}\right)$ in the presence of $\mathrm{CaCl}_{2}(\mathrm{E}-509)$ and $\mathrm{KNO}_{3}$ (E-252; Chy-Max, Chr. Hansen, Hørsholm, Denmark). The curds were cut (10 to $15 \mathrm{~min})$, heated $\left(38\right.$ to $\left.42^{\circ} \mathrm{C}\right)$, dried ( $25 \mathrm{~min})$, pressed $\left(70 \mathrm{~min}, 37\right.$ to $\left.41^{\circ} \mathrm{C}\right)$, drained $(1$ h), salted at $12^{\circ} \mathrm{C}$ for $24 \mathrm{~h}(\mathrm{pH} 4.5$ to 4.9 , salt concentration $>1,151 \mathrm{~g} / \mathrm{mL}$ ), drained and dried (30 min to 24 $\mathrm{h}$ ), and coated with plastic. The ripening of the cheese lasted $4 \mathrm{wk}$ at 10 to $12^{\circ} \mathrm{C}$ at a relative air humidity of 80 to $85 \%$.

The nutrient value of $100 \mathrm{~g}$ of cheese was as follows: lipids, $26 \mathrm{~g}$; proteins, $26.4 \mathrm{~g}$; carbohydrates and fiber, $0 \mathrm{~g}$; saturated fatty acids, $16 \mathrm{~g}$; vitamin A, $0.23 \mathrm{mg}$; vitamin $\mathrm{B}_{2}, 0.37 \mathrm{mg}$, and vitamin $\mathrm{C}, 3 \mathrm{mg}$. The energy provided by consuming $100 \mathrm{~g}$ of the cheese was $350 \mathrm{kcal}$ or $1,488 \mathrm{~kJ}$.

\section{In Vivo Animal Trial}

The biosafety of cheese containing L. plantarum Tensia was evaluated in a mouse model according to guidelines suggested by the Federation of European Laboratory Animal Science Association (Nicklas et al., 2002). The animal trial protocol was approved by the Ethics Committee on Animal Experiments of the Ministry of Agriculture of Estonia (protocol number 67/09.11.06).

Altogether, 20 National Institutes of Health mice (Harlan Laboratories Inc., Blackthorn, UK) were involved. Throughout the study, the mice were given a commercial diet (R-70; Lactamin, Kimstad, Sweden) and tap water ad libitum and a 50-g amount of cheese was added per cage daily. The average consumption of cheese per mouse per day was calculated after the leftover cheese was weighed. Ten mice belonged to the test group fed the probiotic cheese containing L. plantarum Tensia at a concentration of $9.6 \log _{10} \mathrm{cfu} / \mathrm{g}$ for
30 consecutive days. A control group was fed the same amount of regular cheese without added lactobacilli.

Changes in behavior, coat texture, physical activity, and general health of the animals as well as changes in BW and related changes in food and water consumption were observed daily according to the Organisation for Economic Co-operation and Development Guidance Document (OECD, 2000). Feces for counts of lactobacilli were sampled on d $0,3,10,15,20$, and 30 . For histological analysis, tissue sections of the liver, spleen, kidneys, and lungs of killed mice were fixed in $10 \%$ of formaldehyde and embedded in paraffin. The samples were stained with hematoxylin and eosin and by using the van Gieson method. Alterative and inflammatory changes in tissues were evaluated.

Mice were killed by cervical dislocation on d 30, and samples were collected for microbiological analyses. Heart blood $(10 \mu \mathrm{L})$ and homogenized tissue of the liver and spleen were tested for possible translocation of gut microbiota and L. plantarum Tensia onto blood and MRS agar, and for counts of lactobacilli, samples of the small intestine and large intestine were plated onto MRS agar (Oxoid). After $48 \mathrm{~h}$ of incubation in an aerobic (blood agar plates) and a microaerobic environment (MRS plates), colonies were enumerated. The Lactobacillus spp. were identified according to gram staining, colony and cell morphology, a negative catalase reaction, and carbohydrate fermentation patterns.

\section{Design of Human Volunteer Trials}

The present study was conducted according to guidelines laid down in the Declaration of Helsinki. All trials were carried out in accordance with good clinical practice (GCP) and approved by the Ethics Review Committee on Human Research of the University of 
Tartu, Estonia (protocol nos. 158/10 from March 26, 2007; 177/T-13 from December 12, 2008; and 190/10 from 2010). All participants provided written informed consent at the enrollment of the study and were given the possibility of withdrawing from the study at any time.

Three different trials were conducted. Study 1 (TE 1), a double-blind placebo-controlled (DBPC) crossover study [International Standard Randomized Controlled Trial Number (ISRCTN) ISRCTN38739209], was performed to investigate the tolerability and safety of semihard Edam-type cheese containing L. plantarum strain Tensia on healthy adults.

Within 1 mo before the beginning of the study, participants were asked to continue their normal diet except to avoid probiotic products (e.g., food supplements, cheese, yogurt, kefir). The trial began with participants consuming $50 \mathrm{~g}$ of the test cheese [i.e., cheese containing L. plantarum Tensia (verum)] daily for 3 wk. The trial was begun with the test cheese because otherwise the control cheese could have influenced the evaluation of tolerability of the study product under investigation. After a 2-wk washout period, volunteers were crossed over to another $3 \mathrm{wk}$ of consuming the control cheese (i.e., cheese without L. plantarum Tensia; Table 2, Figure 1).

Study 2 (ELD), a second DBPC crossover trial (ISRCTN45791894), was performed to investigate the safety of semihard Edam-type cheese containing $L$. plantarum strain Tensia on health markers in healthy elderly participants. Within 1 mo before the beginning of the study, participants were asked to continue their normal diet except to avoid probiotic products (e.g., food supplements, yogurt, cheese, kefir). The trial began with 3 wk of participants consuming $50 \mathrm{~g}$ of the test cheese [i.e., cheese containing $L$. plantarum Tensia (verum)] daily. The trial was begun with the test cheese

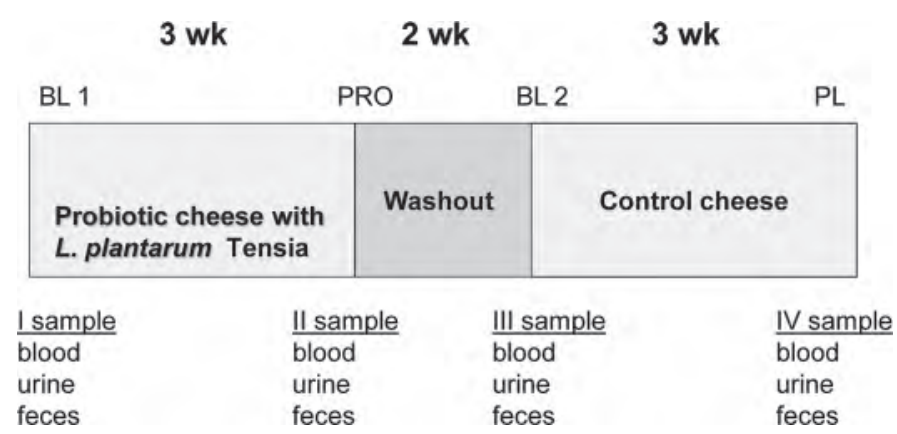

Figure 1. Design of the double-blind placebo-controlled human intervention studies with healthy volunteers (study 1 ) and the elderly (study 2 ). BL $1=$ baseline 1 , at recruitment; PRO = after the probiotic treatment; BL 2 = baseline 2, after washout; PL $=$ after the control treatment. because otherwise the control cheese could have influenced the evaluation of tolerability of the study product under investigation. After a 2-wk washout period, volunteers were crossed over to another 3 wk of control cheese (i.e., cheese without L. plantarum Tensia) consumption (Table 2, Figure 1).

Study 3 (TE 5), an open-label intervention study 3 (ISRCTN42449576), was performed to investigate the safety and dose-response effects of semihard Edam-type cheese containing L. plantarum strain Tensia on health markers in healthy adults. After a 3 -wk run-in period, in which participants were asked to continue their normal diet except to avoid probiotic products (e.g., food supplements, yogurt, kefir), the participants consumed cheese containing a high dose (100 g) of L. plantarum Tensia daily for 3 wk.

\section{Study Population}

The participants were randomly chosen from freeliving healthy adults aged 18 to $65 \mathrm{yr}$. The healthy elderly ( $>65 \mathrm{yr}$ of age) were selected from the registry of family doctors and orthopedists of Tartu University Clinics (Tartu, Estonia) before orthopedic surgery. The demographic and baseline characteristics of participants are described in Table 3.

The overall inclusion criteria were a desire to participate, a suitable age, no known health problems, no health conditions that required medication, and no previous (at least 2 mo) antimicrobial treatment. Subjects following special dietary routines; having an unstable cardiopulmonary system; with a history of diabetes and malignancy, food allergy, acute infection, chronic renal or hepatic failure, or gut surgery; with the presence of an acute illness 4 wk before the study; having used any medication during the last $2 \mathrm{mo}$; or with a history of alcohol abuse, pregnancy, or breastfeeding were excluded from participation. For exclusion of participants with undiagnosed diabetes, glucose and glycohemoglobin were detected in blood sera.

Participants in the trials habitually consumed a Western diet. Diets were typically rich in potatoes, vegetables, meat, and eggs, but also characterized by a high content of fiber (rye bread and oat, wheat, or rice porridge) and high-fat dairy products, vegetable seed oils, margarine, and nonalcoholic beverages (Adlercreutz, 1990; Štšepetova et al., 2011).

\section{Questionnaire}

In all trials, a self-reported questionnaire was administered, which contained questions about participants' welfare and any adverse gastrointestinal symptoms (abdominal pain, flatulence, bloating, stool frequency, and 
Table 3. Demographic and baseline characteristics of participants (mean $\pm \mathrm{SD}$ )

\begin{tabular}{|c|c|c|c|}
\hline Variable & \multicolumn{2}{|c|}{$\mathrm{DBPC}^{1}$ intervention study } & $\frac{\text { Open-label intervention study }}{\text { Study } 3}$ \\
\hline Study acronym & TE 1 & ELD & TE 5 \\
\hline Study population & Adults & Elderly & Adults \\
\hline No. of enrolled participants & 13 & 21 & 29 \\
\hline No. of participants completing the study & 12 & 18 & 26 \\
\hline $\mathrm{BMI}^{3}\left(\mathrm{~kg} / \mathrm{m}^{2}\right)$ & $24.1 \pm 3.6$ & $27.3 \pm 4.2$ & $25.7 \pm 4.6$ \\
\hline Total cholesterol (mmol/L) & $4.6 \pm 0.9$ & $5.8 \pm 0.8$ & $5.6 \pm 1.5$ \\
\hline $\mathrm{HDL}_{\text {cholesterol }}^{4}(\mathrm{mmol} / \mathrm{L})$ & $1.7 \pm 0.5$ & $1.7 \pm 0.3$ & $1.7 \pm 0.5$ \\
\hline LDL cholesterol $^{5}(\mathrm{mmol} / \mathrm{L})$ & $2.7 \pm 0.8$ & $3.9 \pm 0.8$ & $3.6 \pm 1.5$ \\
\hline Triglycerides $(\mathrm{mmol} / \mathrm{L})$ & $1.0 \pm 0.6$ & $1.1 \pm 0.6$ & $1.2 \pm 0.9$ \\
\hline $\mathrm{HbA1c} \mathrm{c}^{6}$ & $5.6 \pm 0.4$ & $5.7 \pm 0.2$ & $5.6 \pm 0.2$ \\
\hline
\end{tabular}

${ }^{1} \mathrm{DBPC}=$ double-blind placebo-controlled.

${ }^{2}$ ISRCTN $=$ International Standard Randomized Controlled Trial Number.

${ }^{3} \mathrm{BMI}=$ body mass index.

${ }^{4} \mathrm{HDL}=$ high-density lipoprotein.

${ }^{5} \mathrm{LDL}=$ low-density lipoprotein.

${ }^{6} \mathrm{HbA} 1 \mathrm{c}=$ glycohemoglobin.

stool consistency). Questionnaires were completed once a week during the trial (Svedlund et al., 1988)

\section{Clinical Investigations}

The subjects were clinically investigated, and plasma samples were collected after an overnight fast and after abstinence from any medications, tobacco, alcohol, tea, or coffee. Each participant was evaluated for anthropometrical indices. Body mass index (BMI) was calculated as the $\mathrm{BW}(\mathrm{kg})$ divided by the height squared $\left(\mathrm{m}^{2}\right)$. Overweight was classified as a BMI $\geq 25.0$ and normal weight was classified as a BMI $<25.0$ according to the World Health Organization Global Database on Body Mass Index (http://apps.who.int/bmi/index. jsp?introPage=intro_3.html). In TE 5, the hip and waist circumference $(\mathrm{cm})$ was measured and the waistto-hip ratio was calculated.

In the DBPC trials (TE 1 and ELD), fasting blood samples were collected at recruitment, after administration of the cheese containing L. plantarum Tensia, after a washout period, after administration of the control cheese, and at the end of the trial. In the open-label trials (TE 5), blood samples were collected at recruitment and after the intervention.

Hematological indices (hemoglobin, erythrocytes, leukocytes, lymphocytes), inflammatory indices (white blood cell count and hs-CRP), metabolic markers [plasma glucose, glycohemoglobin, and lipids, namely, total cholesterol, low-density lipoprotein (LDL) cholesterol, high-density lipoprotein (HDL) cholesterol, and tri- glycerides], and functionality markers [liver and kidney functions: aspartate aminotransferase (AST), alanine aminotransferase (ALT), albumin, serum creatinine, and immunoglobulin (IgE, IgA, IgM, IgG) levels] were determined by standard laboratory methods using certified assays in the local clinical laboratory (United Laboratories of Tartu University Clinics). Intervals for routine laboratory tests proposed by the Nordic Reference Interval Project (http://www.furst.no/norip/) were used as a reference.

\section{Microbiological Analyses of Feces}

Quantitative analysis of fecal cultivable lactobacilli was performed using conventional serial dilution and cultivation methods on MRS media. Samples of feces were serially diluted $\left(10^{-2}\right.$ to $\left.10^{-9}\right)$ in PBS ( $\left.\mathrm{pH} 7.2\right)$ in an anaerobic glove box (Concept 400, Biotrace International PLC, Bridgend, UK) with a gas mixture consisting of $5 \% \mathrm{CO}_{2}, 5 \% \mathrm{H}_{2}$, and $90 \% \mathrm{~N}_{2}$, and then cultivated on freshly prepared MRS agar media (Oxoid). The bacteria were quantified by serial dilutions. The microbial counts were expressed as log colony-forming units per gram of feces. The detection limit of microorganisms was $3.0 \mathrm{log} \mathrm{cfu} / \mathrm{g}$. Lactobacilli were identified according to their biochemical profile by API CHL 50 medium (bioMérieux SA, Marcy L'Étoile, France).

Survival of the L. plantarum Tensia strain in the human gastrointestinal tract was confirmed by randomly amplified polymorphic DNA-PCR in TE 1 as follows. Genomic DNA of putative Tensia fecal isolates was 
extracted from 24-h-old cultures and cultivated microaerobically on MRS agar with a QIAamp DNA Mini Kit 50 (Qiagen $\mathrm{GmbH}$ ) according to the manufacturer's instructions.

Randomly amplified polymorphic DNA-PCR typing was done with primer M13 (GAGGGTGGCGGTTCT; DNA Technology A/S, Risskov, Denmark). A 50$\mu \mathrm{L}$ volume of the reaction mixture consisted of $10 \times$ PCR buffer (Fermentas), $5 \mathrm{mM} \mathrm{MgCl}_{2}$ (Fermentas), $200 \mu M$ deoxynucleoside triphosphate mixture [2'-deoxyadenosine triphosphate (dATP), deoxyguanosine triphosphate (dGTP), 2'-deoxythymidine triphosphate (dTTP), and 2'-deoxycytidine 5 '-triphosphate (dCTP); Fermentas], $2.0 \mu \mathrm{mol} / \mathrm{L}$ of each primer, $1.25 \mathrm{U}$ of Taq DNA Polymerase (Fermentas), and 100 ng of extracted DNA. The PCR mixture was subjected to thermal cycling (Cycler 200r, Eppendorf AG) with 40 cycles of denaturation and polymerase activation at $95^{\circ} \mathrm{C}$ for 5 min, annealing at $42^{\circ} \mathrm{C}$ for $2 \mathrm{~s}$, and extension at $72^{\circ} \mathrm{C}$ for $10 \mathrm{~min}$, with a final extension at $72^{\circ} \mathrm{C}$ for $10 \mathrm{~min}$. The PCR products were separated by electrophoresis in a horizontal $2 \%$ agarose gel containing $0.1 \mu \mathrm{L} / \mathrm{mL}$ of ethidium bromide in a Tris-acetic acid-EDTA buffer (40 $\mathrm{m} M$ Tris, $20 \mathrm{~m} M$ boric acid, $1 \mathrm{~m} M$ EDTA, pH 8.3; Bio-Rad Laboratories, Hercules, CA) at a constant voltage of 120 V. A 1-kb ladder (GeneRuler; Fermentas) was used as the base pair size marker. The banding patterns of the isolates were visualized with UV light and compared with those of the L. plantarum Tensia.

\section{Statistical Analysis}

The sample size was calculated for crossover studies based on a predicted change in cholesterol of $0.1 \mathrm{U}$ in the treatment period. Assuming a standard deviation of $0.09 \mathrm{U}$, a sample size of 8 subjects provided sufficient power $(80 \%)$ to detect a significance level of $\mathrm{P}<$ 0.05 in a paired Student's $t$-test calculation. Statistical analysis was performed with $\mathrm{R}$ software version 2.9.0 (A Language and Environment, R Project for Statistical Computing; http://www.r-project.org). Clinical and biochemical data were expressed as means \pm standard deviations. Intestinal lactobacilli counts were expressed as log colony-forming units per gram of feces. Baseline and intervention data were compared by paired $t$-test or Wilcoxon rank-sum test, according to distribution of data.

All data were given as means and standard deviations. Differences were considered statistically significant if the value was $P<0.05$. The $\chi^{2}$-test was used to determine the between-group differences in categorical variables (gastrointestinal symptoms). Study power was calculated with the program PS: Power and Sample Size
Calculation (version 3.0; http://biostat.mc.vanderbilt. edu/PowerSampleSize).

\section{RESULTS}

\section{Hemolytic Activity}

Lactobacillus plantarum Tensia did not cause the lysis of erythrocytes of human and sheep blood in either of the environments, whereas complete lysis ( $\beta$-hemolysis) was caused by the strains of Strep. pyogenes and Staph. aureus that were used as positive controls.

\section{Antibacterial Susceptibility}

The L. plantarum Tensia strain was susceptible to all the tested antibiotics. The MIC values corresponded to epidemiological cutoff (ECOFF) values for differentiation of wild-type lactobacilli isolates and cultures intended for probiotic or nutritional use (Klare et al., 2005): kanamycin $32 \mu \mathrm{g} / \mathrm{mL}$ (ECOFF $64 \mu \mathrm{g} / \mathrm{mL}$ ), ampicillin $0.25 \mu \mathrm{g} / \mathrm{mL}$ (ECOFF $2 \mu \mathrm{g} / \mathrm{mL}$ ), gentamicin $1.5 \mu \mathrm{g} / \mathrm{mL}$ (ECOFF $8 \mu \mathrm{g} / \mathrm{mL}$ ), streptomycin 16 $\mu \mathrm{g} / \mathrm{mL}$ (ECOFF $64 \mu \mathrm{g} / \mathrm{mL}$ ), erythromycin $0.19 \mu \mathrm{g} /$ $\mathrm{mL}$ (ECOFF $32.5 \mu \mathrm{g} / \mathrm{mL}$ ), clindamycin $0.032 \mu \mathrm{g} / \mathrm{mL}$ (ECOFF $0.5 \mu \mathrm{g} / \mathrm{mL}$ ), tetracycline $8 \mu \mathrm{g} / \mathrm{mL}$ (ECOFF $32 \mu \mathrm{g} / \mathrm{mL}$ ), chloramphenicol $2 \mu \mathrm{g} / \mathrm{mL}$ (ECOFF $8 \mu \mathrm{g} /$ $\mathrm{mL}$ ), and quinupristin/dalfopristin $1 \mu \mathrm{g} / \mathrm{mL}$ (ECOFF $1 \mu \mathrm{g} / \mathrm{mL})$.

\section{Class I Integron and Tetracycline-Resistance Genes}

Lactobacillus plantarum Tensia did not possess the tetracycline-resistance-determining genes tet $(\mathrm{L}), \operatorname{tet}(\mathrm{S})$, or $\operatorname{tet}(\mathrm{O})$, although the $\operatorname{tet}(\mathrm{K})$ and $\operatorname{tet}(\mathrm{M})$ genes were found. The strain did not contain the integron Int1 gene.

\section{Production of BA}

In Decarboxylation Medium. After $4 \mathrm{~d}$ at $37^{\circ} \mathrm{C}$, L. plantarum Tensia produced traces of cadaverine in vitro from lysine $(0.3 \mu \mathrm{g} / \mathrm{mL})$ and produced putrescine from ornithine $(0.5 \mu \mathrm{g} / \mathrm{mL})$. The strain did not decarboxylate arginine or glutamine. Histamine was not produced from histidine. The gram-positive control strain L. plantarum DSM 21379 produced putrescine from ornithine $(1.9 \mu \mathrm{g} / \mathrm{mL})$. The control strain E. coli ATCC 700336 was able to produce significant amounts of cadaverine from lysine $(240 \mu \mathrm{g} / \mathrm{mL})$, putrescine from arginine and ornithine $(18.4$ and $1,599.3 \mu \mathrm{g} / \mathrm{mL}$, respectively), and histamine from histidine $(105.1 \mu \mathrm{g} /$ $\mathrm{mL})$. 
In Milk. After incubating the Tensia strain in milk at $37^{\circ} \mathrm{C}$, tyramine was detected at a concentration of $6.9 \mu \mathrm{g} / \mathrm{mL}$ on $\mathrm{d} 12$. This concentration decreased to 1.5 $\mu \mathrm{g} / \mathrm{mL}$ by d 40 . No other BA were detected.

In Cheese. The formation of most BA, including cadaverine and histamine, in cheese during ripening and storage was not established. Only tyramine and putrescine were found in 3 batches of cheese containing Tensia in detectable amounts $(0.69,2.65$, and 5.49 $\mathrm{mg} / \mathrm{kg}$ of tyramine and $1.32,7.46$, and $7.29 \mathrm{mg} / \mathrm{kg}$ of putrescine, respectively) at the end of ripening (wk 4). The corresponding figures for tyramine and putrescine in control cheese (regular Edam-type cheese) were 2.31, 5.64 , and $0.1 \mathrm{mg} / \mathrm{kg}$ of tyramine and $1.82,1.84$, and 0.1 $\mathrm{mg} / \mathrm{kg}$ of putrescine, respectively.

\section{In Vivo Animal Trial}

The average consumption rate of cheese per mouse was approximately $4.4 \mathrm{~g} / \mathrm{d}$. Oral administration of $L$. plantarum Tensia with cheese did not influence the activity or general health status of the treated mice over $30 \mathrm{~d}$. The mean BW of the mice in the test group was $25.6 \pm 1.5 \mathrm{~g}$ at the beginning and $32.9 \pm 1.6 \mathrm{~g}$ at the end of the trial. Respective values for the controls were $26.9 \pm 1.3 \mathrm{~g}$ and $32.8 \pm 1.7 \mathrm{~g}$. Average daily BW gain for both groups (test group and control group) was 1.5 g. The BW gained at the end of the trial was 6.1 and $6.2 \mathrm{~g}$, respectively. Thus, all mice showed an increase in BW.

No statistically significant increase was found in the total count of lactobacilli from the small intestine (range/median: 3.0-7.1/5.9 log cfu/g in the control group vs. $0-5.7 / 4.7 \mathrm{log} \mathrm{cfu} / \mathrm{g}$ in the test group) and from the large intestine when compared with the control group (4.4-7.3/6.6 log cfu/g in the control group vs. $0-7.0 / 6.7 \log \mathrm{cfu} / \mathrm{g}$ in the test group).

No translocation of the administered strain or other microbes into the blood or organs was detected. The heart blood, liver, kidney, and lung samples obtained at autopsy were sterile in all mice. No pathological shifts and no micro abscesses, granulomas, or inflammation were found by morphological and histological evaluation of the spleen, liver, ileum, and colon of mice.

\section{In Vivo Human Trial Clinical Investigations}

Questionnaires. In adults (TE 1), no complaints were reported regarding abdominal pain or bloating throughout the 3 -wk treatment period [verum (i.e., cheese containing L. plantarum Tensia) vs. control (i.e., regular) cheese; $P=1.0]$, and no complaints were reported regarding flatulence in wk 1 and 3 (verum vs. control; $P=1.0$ ). However, in wk 2 of the treatment,
$25 \%$ of participants reported flatulence in the verum period (verum vs. control; $P=0.22$ ). No significant changes in stool frequency or consistency were reported.

In adults with a high dose of probiotic cheese (TE 5), $8 \%$ of participants reported abdominal pain throughout the 3 -wk treatment period; flatulence and bloating were reported by $27 \%$ of participants throughout the 3 -wk treatment period. Approximately $62 \%$ of participants reported hard stools in wk 2 and 3 of the trial in comparison with the run-in period $(P=0.023)$.

In the study with the elderly (ELD), participants reported no significant abdominal pain (23\%, verum vs. control; $P=1.0)$, flatulence $(50 \%$, verum vs. control; $P=1.0$ ), or bloating ( $20 \%$, verum vs. control; $P$ $=1.0)$ throughout the trial in both treatment periods (probiotic and control). No significant changes in stool frequency or consistency were reported.

Abdominal Obesity and BMI. No significant changes were detected in BMI (TE 1: baseline $24.1 \pm$ 3.6 to $24.2 \pm 3.6 \mathrm{~kg} / \mathrm{m}^{2}, P=0.584$; ELD: $27.6 \pm 4.1$ vs. $27.5 \pm 4.2 \mathrm{~kg} / \mathrm{m}^{2}, P=0.723$; TE $5: 25.7 \pm 4.6$ vs. $\left.25.7 \pm 4.7 \mathrm{~kg} / \mathrm{m}^{2}, P=0.319\right)$ following the 3 -wk consumption of probiotic cheese. The additional markers of abdominal obesity, namely, waist circumference $(\mathrm{cm})$ and waist-to-hip ratio, in adults consuming the highest dose of $100 \mathrm{~g} / \mathrm{d}$ for $3 \mathrm{wk}$ (TE 5) also did not increase (baseline $0.808 \pm 0.075$ vs. end of trial $0.806 \pm 0.073$; $P=0.351)$

Blood Serum Glucose and Lipids. In TE 1, no changes in the level of blood serum glucose were detected (probiotic period: $4.5 \pm 0.7$ vs. $4.6 \pm 0.5 \mathrm{mmol} / \mathrm{L}, P$ $=0.922$; control period: $4.6 \pm 0.6$ vs. $4.7 \pm 0.5 \mathrm{mmol} / \mathrm{L}$, $P=0.289$; Table 4).

In the elderly (ELD), a significant increase of $0.3 \mathrm{U}$ was found in blood serum glucose content (from $5.1 \pm$ 0.5 to $5.4 \pm 0.5 \mathrm{mmol} / \mathrm{L}, P=0.036)$ after probiotic cheese consumption (Table 4). However, the increase did not exceed the normal reference values by the Nordic Reference Interval Project (M/F $>18$ yr: 3.3 to 5.5 $\mathrm{mmol} / \mathrm{L}$ ). On the other hand, in adult volunteers (TE $5)$, a statistically significant reduction $(P=0.0005)$ in blood serum glucose (from $5.3 \pm 0.4$ to $5.0 \pm 0.5$ $\mathrm{mmol} / \mathrm{L}$ ) was registered after $3 \mathrm{wk}$ of probiotic cheese consumption at the high dose (Table 4). No correlations between the changes in glucose contents with age, sex, or gastrointestinal health status and BMI were established. Blood serum lipid (total, HDL, and LDL cholesterol) levels remained unchanged in all groups consuming probiotic cheese in comparison with the recruitment values (Table 4).

Inflammation Markers. After the 3-wk probiotic treatment, the values of systemic inflammation markers (hs-CRP and white blood cell count) stayed within the normal range in both adults and the elderly (Table 5). 
Table 4. Effect of $3 \mathrm{wk}$ of consumption of $50 \mathrm{~g}$ [studies 1 (TE 1) and 2 (ELD)] or $100 \mathrm{~g}$ [study 3 (TE 5)] of probiotic cheese containing Lactobacillus plantarum Tensia on blood serum glucose and lipid values of adult volunteers (TE 1, TE 5) and the elderly (ELD; mean \pm SD)

\begin{tabular}{|c|c|c|c|c|c|c|c|}
\hline \multirow[b]{2}{*}{ Variable $^{2}$} & \multicolumn{2}{|c|}{ Test period } & \multirow{2}{*}{$\begin{array}{c}P \text {-value, } \\
\text { PRO vs. BL1 }\end{array}$} & \multicolumn{2}{|c|}{ Control period } & \multirow{2}{*}{$\begin{array}{c}P \text {-value, } \\
\text { BL2 vs. PL }\end{array}$} & \multirow[b]{2}{*}{ Reference interval by NORIP ${ }^{3}$} \\
\hline & BL1 & PRO & & BL2 & PL & & \\
\hline \multicolumn{8}{|l|}{ TE $1(\mathrm{n}=12)$} \\
\hline Total cholesterol $(\mathrm{mmol} / \mathrm{L})$ & $4.6 \pm 0.9$ & $4.6 \pm 1.1$ & 0.828 & $4.2 \pm 0.6$ & $4.5 \pm 0.9$ & 0.102 & 30 to $<50 \mathrm{yr}: 3.3$ to $6.9 \cdot \mathrm{mmol} / \mathrm{L}$ \\
\hline HDL cholesterol (mmol/L) & $1.7 \pm 0.5$ & $1.7 \pm 0.3$ & 0.628 & $1.6 \pm 0.4$ & $1.7 \pm 0.4$ & 0.433 & $\geq 18$ yr: $1.2 \mathrm{mmol} / \mathrm{L}$ \\
\hline LDL cholesterol $(\mathrm{mmol} / \mathrm{L})$ & $2.7 \pm 0.8$ & $2.8 \pm 1.1$ & 0.296 & $2.6 \pm 0.7$ & $2.6 \pm 0.7$ & 0.827 & 30 to $\leq 50$ yr: 1.4 to $4.7 . \mathrm{mmol} / \mathrm{L}$ \\
\hline $\mathrm{TG}(\mathrm{mmol} / \mathrm{L})$ & $1.0 \pm 0.6$ & $1.0 \pm 0.5$ & 0.978 & $0.9 \pm 0.4$ & $1.2 \pm 0.7$ & 0.140 & $\geq 18$ yr: 0.45 to $2.6 . \mathrm{mmol} / \mathrm{L}$ \\
\hline Glycose $(\mathrm{mmol} / \mathrm{L})$ & $4.5 \pm 0.7$ & $4.6 \pm 0.5$ & 0.922 & $4.6 \pm 0.6$ & $4.7 \pm 0.5$ & 0.289 & $\geq 18$ yr: 3.3 to $5.5 \mathrm{mmol} / \mathrm{L}$ \\
\hline \multicolumn{8}{|l|}{$\operatorname{ELD}(\mathrm{n}=18)$} \\
\hline Total cholesterol $(\mathrm{mmol} / \mathrm{L})$ & $5.7 \pm 0.8$ & $5.6 \pm 0.8$ & 0.343 & $5.9 \pm 0.9$ & $5.7 \pm 0.8$ & 0.198 & $>50$ yr: 3.9 to $7.8 \mathrm{mmol} / \mathrm{L}$ \\
\hline HDL cholesterol $(\mathrm{mmol} / \mathrm{L})$ & $1.7 \pm 0.4$ & $1.6 \pm 0.4$ & 0.411 & $1.7 \pm 0.4$ & $1.7 \pm 0.5$ & 0.514 & $\geq 18$ yr: $1.2 \mathrm{mmol} / \mathrm{L}$ \\
\hline LDL cholesterol $(\mathrm{mmol} / \mathrm{L})$ & $3.9 \pm 0.8$ & $3.8 \pm 0.7$ & 0.557 & $4.1 \pm 0.9$ & $3.8 \pm 0.7$ & 0.052 & $\geq 50$ yr: 2.0 to $5.3 \mathrm{mmol} / \mathrm{L}$ \\
\hline $\mathrm{TG}(\mathrm{mmol} / \mathrm{L})$ & $1.1 \pm 0.6$ & $1.1 \pm 0.6$ & 0.380 & $1.2 \pm 0.5$ & $1.1 \pm 0.5$ & 0.394 & $\geq 18$ yr: 0.45 to $2.6 . \mathrm{mmol} / \mathrm{L}$ \\
\hline Glycose $(\mathrm{mmol} / \mathrm{L})$ & $5.1 \pm 0.5$ & $5.4 \pm 0.5$ & 0.036 & $5.3 \pm 0.5$ & $5.4 \pm 0.4$ & 0.144 & $\geq 18$ yr: 3.3 to $5.5 \mathrm{mmol} / \mathrm{L}$ \\
\hline \multicolumn{8}{|l|}{$\operatorname{TE} 5(\mathrm{n}=26)$} \\
\hline Total cholesterol $(\mathrm{mmol} / \mathrm{L})$ & $5.6 \pm 1.5$ & $5.5 \pm 1.4$ & 0.151 & $\mathrm{ND}^{4}$ & ND & - & 30 to $\leq 50$ yr: 3.3 to $6.9 \mathrm{mmol} / \mathrm{L}$ \\
\hline HDL cholesterol $(\mathrm{mmol} / \mathrm{L})^{\prime}$ & $1.7 \pm 0.5$ & $1.7 \pm 0.4$ & 0.187 & ND & ND & - & $\geq 18$ yr: $1.2 \mathrm{mmol} / \mathrm{L}$ \\
\hline LDL cholesterol $(\mathrm{mmol} / \mathrm{L})$ & $3.6 \pm 1.5$ & $3.7 \pm 1.4$ & 0.761 & ND & ND & - & 30 to $\leq 50$ yr: 1.4 to $4.7 \mathrm{mmol} / \mathrm{L}$ \\
\hline $\mathrm{TG}(\mathrm{mmol} / \mathrm{L})$ & $1.2 \pm 0.9$ & $1.0 \pm 0.5$ & 0.183 & ND & ND & - & $\geq 18$ yr: 0.45 to $2.6 \mathrm{mmol} / \mathrm{L}$ \\
\hline Glycose (mmol/L) & $5.3 \pm 0.4$ & $5.0 \pm 0.5$ & 0.0005 & ND & ND & - & $\geq 18$ yr: 3.3 to $5.5 \mathrm{mmol} / \mathrm{L}$ \\
\hline
\end{tabular}

BL1 = baseline 1, at recruitment: $\mathrm{PRO}=$ after the probiotic treatment; $\mathrm{BL} 2=$ baseline 2 , after washout: $\mathrm{PL}=$ after the control treatment

${ }^{2} \mathrm{HDL}=$ high-density lipoprotein; LDL $=$ low-density lipoprotein; TG $=$ triglycerides.

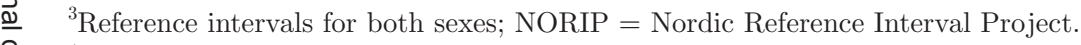

${ }^{4} \mathrm{ND}=$ not determined. 
In both age groups, no changes in the contents of IgA, IgM, and IgG antibodies were detected. Most important, no change was detected in the values of the essential allergy marker IgE or in kidney and liver markers (serum creatinine, albumin, ALT, or AST; Table 6 ). Even consumption of the higher dose of probiotic cheese had no negative effect on the aforementioned indices (Table 6).

Intestinal Lactobacilli. The total counts of intestinal cultivable lactobacilli increased significantly during the period of probiotic cheese consumption for both adults (TE $1 ; 5.5 \pm 1.1$ vs. $6.7 \pm 1.0 \log \mathrm{cfu} / \mathrm{g}$, $P=0.047$ ) and the elderly (ELD; mean value $5.2 \pm$ 2.7 vs. $6.9 \pm 1.4 \log \mathrm{cfu} / \mathrm{g}, P=0.017$; Figure 2$)$. No significant changes were seen with the consumption of control cheese.

The cheese strain administered, L. plantarum Tensia, was detectable in the fecal samples of 10 of 12 adult participants (TE 1) after probiotic consumption, at counts of $6.0 \pm 1.5 \log$ cfu (range: 3.2 to 8.6; median: 6.3 ), and after a 2 -wk washout period, was detectable in the fecal samples of 2 subjects, at counts of $4.2 \pm 0.2$ log cfu (range: 4.0 to 4.3 ; median: 4.2).

\section{DISCUSSION}

We found that the addition of a particular probiotic strain to cheese did not affect the gut functionality indices or metabolism of the host. In this study, we applied the L. plantarum strain Tensia, originating from a healthy child (Mikelsaar et al., 2002). The human origin of the strain is a prerequisite for its harmless status and suitability for oral application. Generally, L. plantarum is a common indigenous component of human intestinal microbiota (Mikelsaar et al., 2002, 2010; de Vries et al., 2006). Moreover, L. plantarum as a species is considered by the European Food Safety Authority suitable for the qualified presumption of safety (QPS) approach (EFSA, 2007).

In characterizing a probiotic strain, the absence of antibiotic-resistance genes is of utmost importance. Mobile genetic elements containing genes determining resistance to erythromycin, tetracycline, and vancomycin have been found among lactobacilli (Tannock, et al., 1994; Gevers et al., 2003a,b; Mathur and Singh, 2005). The prevalence of tet genes in Lactobacillus isolates has been reported earlier (Klare et al., 2005; Gevers et al., 2003a,b). In L. plantarum Tensia, the tet(K) and tet(M) genes, although present, were not expressed. Gevers et al. (2003a,b) showed, in Lactobacillus isolates with the chromosomal tet gene, significantly lower tetracycline MIC values than in the case of plasmid-encoded tetracycline resistance (32 to $48 \mu \mathrm{g} / \mathrm{mL}$ and $>192 \mathrm{~g} / \mathrm{mL}$, respectively). Thus, because we did not find phenotypic

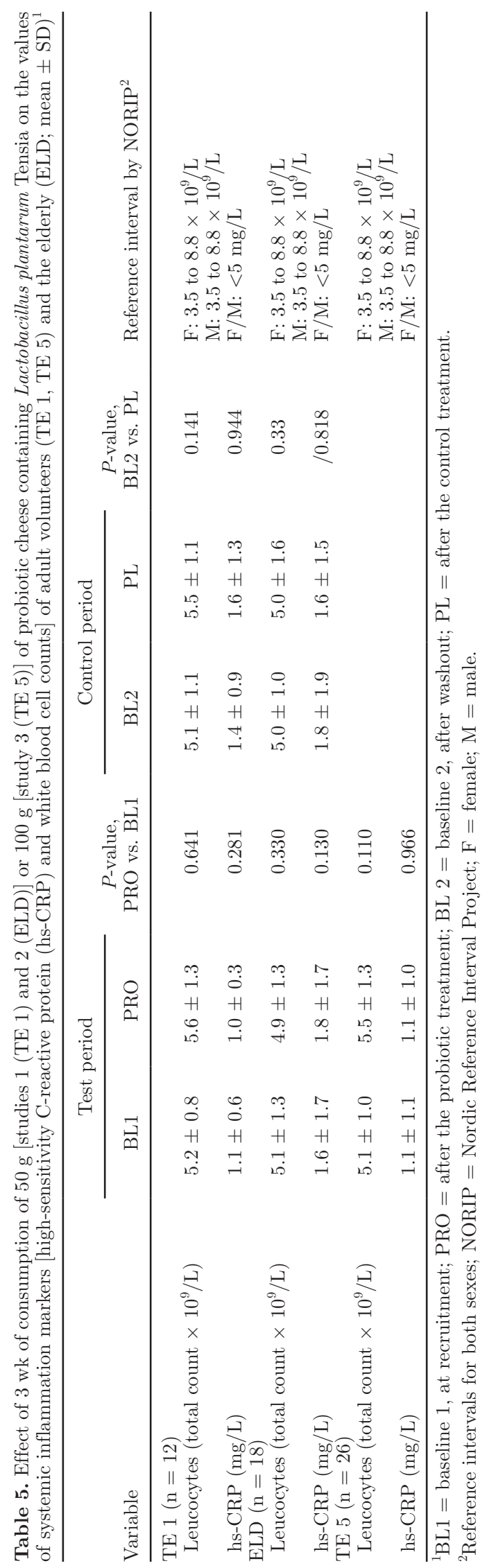

Journal of Dairy Science Vol. 95 No. 10, 2012 
Table 6. Effect of $3 \mathrm{wk}$ of consumption of $50 \mathrm{~g}$ [studies 1(TE 1) and 2 (ELD)] or $100 \mathrm{~g}$ [study 3 (TE 5)] of probiotic cheese containing Lactobacillus plantarum Tensia on metabolic markers of adult volunteers (TE 1, TE 5) and the elderly (ELD; mean $\pm \mathrm{SD})^{1}$

\begin{tabular}{|c|c|c|c|c|c|}
\hline \multirow[b]{2}{*}{ Variable $^{2}$} & \multicolumn{2}{|c|}{ Probiotic cheese } & \multicolumn{2}{|c|}{ Control cheese } & \multirow[b]{2}{*}{$P$-value } \\
\hline & BL1 & PRO & BL2 & PL & \\
\hline \multicolumn{6}{|l|}{ TE 1} \\
\hline $\mathrm{AST}(\mathrm{U} / \mathrm{L})$ & $20.2 \pm 5.4$ & $\mathrm{ND}^{3}$ & ND & $18.3 \pm 5.4$ & 0.129 \\
\hline $\operatorname{ALT}(\mathrm{U} / \mathrm{L})$ & $17.7 \pm 5.6$ & ND & ND & $16.2 \pm 4.34$ & 0.247 \\
\hline Albumin $(\mathrm{g} / \mathrm{L})$ & $45.9 \pm 2.6$ & ND & ND & $45.2 \pm 1.8$ & 0.283 \\
\hline Serum creatinine $(\mu \mathrm{mol} / \mathrm{L})$ & $73.8 \pm 12.0$ & ND & ND & $70.9 \pm 10.3$ & 0.122 \\
\hline $\operatorname{IgE}(\mathrm{kU} / \mathrm{L})$ & $31.7 \pm 21.1$ & ND & ND & $28.9 \pm 19.9$ & 0.174 \\
\hline $\operatorname{IgA}(\mathrm{g} / \mathrm{L})$ & $1.7 \pm 0.7$ & ND & ND & $1.7 \pm 0.6$ & 0.29 \\
\hline $\operatorname{IgM}(\mathrm{g} / \mathrm{L})$ & $1.4 \pm 0.7$ & ND & ND & $1.4 \pm 0.7$ & 0.966 \\
\hline $\operatorname{IgG}(g / L)$ & $11.2 \pm 1.6$ & ND & ND & $11.1 \pm 1.5$ & 0.671 \\
\hline \multicolumn{6}{|l|}{ ELD } \\
\hline $\mathrm{AST}(\mathrm{U} / \mathrm{L})$ & $21.4 \pm 4.2$ & ND & ND & $22.1 \pm 4.4$ & 0.334 \\
\hline ALT (U/L) & $20.2 \pm 8.7$ & ND & ND & $22.8 \pm 9.4$ & 0.050 \\
\hline Albumin $(\mathrm{g} / \mathrm{L})$ & $42.0 \pm 2.3$ & ND & ND & $41.7 \pm 2.8$ & 0.548 \\
\hline Serum creatinine $(\mu \mathrm{mol} / \mathrm{L})$ & $65.4 \pm 9.7$ & ND & ND & $64.6 \pm 10.9$ & 0.779 \\
\hline $\operatorname{IgE}(\mathrm{kU} / \mathrm{L})$ & $53.9 \pm 85.8$ & ND & ND & $42.8 \pm 63.6$ & 0.064 \\
\hline $\operatorname{Ig} \mathrm{A}(\mathrm{g} / \mathrm{L})$ & $2.4 \pm 1.3$ & ND & ND & $2.4 \pm 1.2$ & 0.664 \\
\hline $\operatorname{IgM}(\mathrm{g} / \mathrm{L})$ & $1.2 \pm 0.6$ & ND & ND & $1.2 \pm 0.6$ & 0.205 \\
\hline $\operatorname{IgG}(g / L)$ & $10.3 \pm 1.5$ & ND & ND & $10.8 \pm 1.5$ & 0.098 \\
\hline \multicolumn{6}{|l|}{ TE 5} \\
\hline $\operatorname{AST}(\mathrm{U} / \mathrm{L})$ & $21.9 \pm 6.3$ & $22.8 \pm 6.0$ & ND & & 0.319 \\
\hline $\operatorname{ALT}(\mathrm{U} / \mathrm{L})$ & $21.2 \pm 9.4$ & $22.0 \pm 11.3$ & ND & & 0.508 \\
\hline Albumin (g/L) & $44.5 \pm 2.0$ & $43.9 \pm 2.0$ & ND & & 0.390 \\
\hline Serum creatinine $(\mu \mathrm{mol} / \mathrm{L})$ & $69.8 \pm 14.6$ & $67.5 \pm 12.7$ & ND & & 0.128 \\
\hline
\end{tabular}

tetracycline resistance in L. plantarum Tensia, it can be predicted as nontransferable. However, more studies are needed to verify this prediction.

Probiotics, as viable microbes with the ability to survive and be metabolically active in the gastrointestinal tract, have led to several areas of concern (Hibberd and Davidson, 2008). First is the potential of the probiotic to translocate and cause invasive infection (Salminen et al., 2004; Cannon et al., 2005). The absence of translocation and the absence of histologically detected pathologies in the NIH mouse experimental model proved the safety of the strain L. plantarum Tensia. Moreover, interaction with the gastrointestinal mucosa and the effect on the composition of the intestinal microbiota may also have serious consequences. Feeding the Lactobacillus strain of human origin for a period of $30 \mathrm{~d}$ did not result in an increase in the total number of lactobacilli in the mouse gut. This could be due to the human origin of the strain but also to strain specificity. It has been shown that feeding a human strain of Lactobacillus to mice does not always result in an increase in total counts of lactobacilli (Truusalu et al., 2004).

In our human study, the content of total lactobacilli increased in feces, and the presence of the ingested probiotic strain was confirmed after the consumption of cheese. Mutual interactions take place between a probiotic strain and the indigenous microbiota of the host in the small intestine. The consumption of probiotics may influence the metabolism and population of the indigenous microbiota.

It has been shown that ingestion of a certain probiotic may increase the total number of indigenous lactobacilli (Sepp et al., 1993; Goossens et al., 2003; Wind et al., 2010). The increase in Bifidobacterium and Lactobacillus spp. levels in the gut are correlated with numerous health markers. Microbiota changes attributable to probiotic intake include increased numbers of related phylotypes, a decrease in pathogens and their toxins, stabilization of the bacterial communities when perturbed (e.g., with antibiotics), and the promotion of a more rapid recovery from a perturbation (Floch et al., 2011).

A relatively high amount (10.3 log cfu/serving for 3 wk) of the probiotic strain in the cheese was consumed by adult volunteers. For the elderly, who are a more vulnerable population group, the daily dose was lowered: $8.17 \mathrm{log}$ cfu daily for 3 wk. No adverse side effects (flatulence, bloating, abdominal pain, stool frequency) were detected with $50 \mathrm{~g}$ of cheese consumption in adults. The consumption of cheese in a double dose caused 
a)

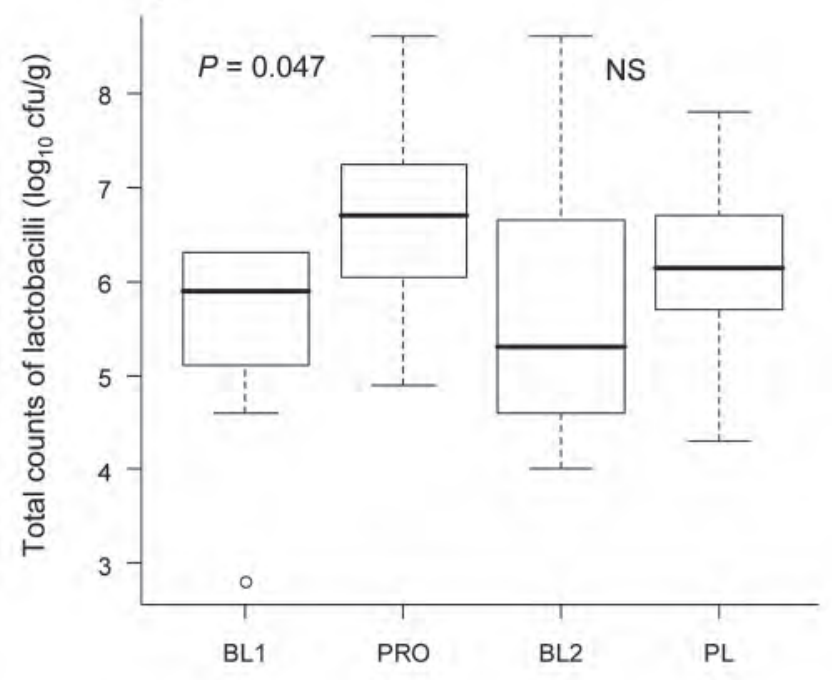

b)

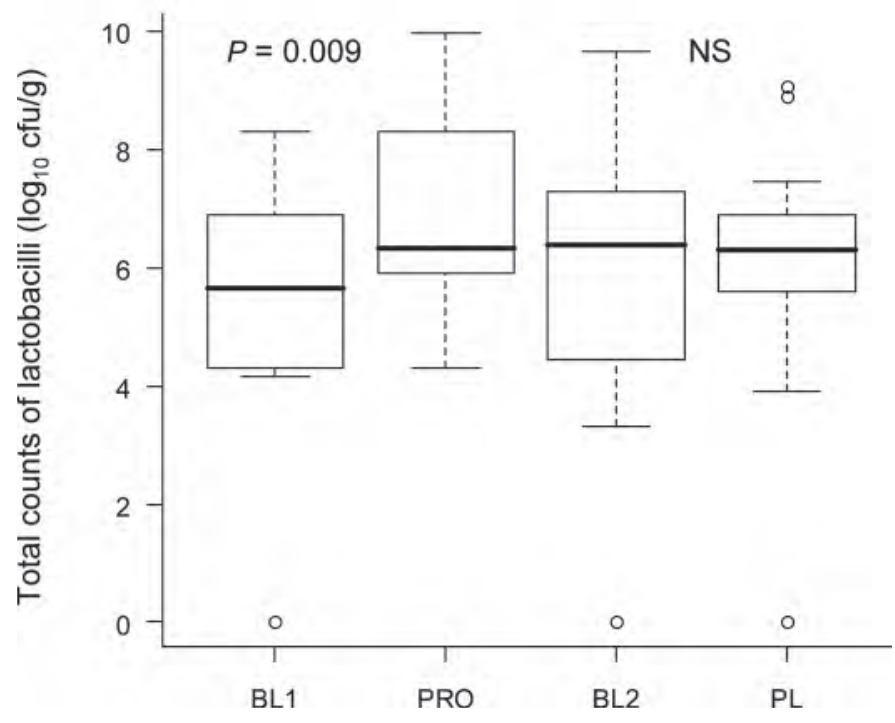

Figure 2. Changes in counts of cultivable fecal lactobacilli during the studies: a) study 1 (TE 1$)$; b) study 2 (ELD). BL $1=$ baseline 1 , at recruitment; $\mathrm{PRO}=$ after the probiotic treatment; BL $2=$ baseline 2 , after washout; $\mathrm{PL}=$ after the control treatment. The transverse line within the box indicates the median value; the bars extending from each box represent the 25th and 75 th percentiles; and the open circles represent outliers.

single cases abdominal pain, flatulence, bloating, or their combination. Because the daily dose of probiotic was similar in both studies with adult volunteers, such indigestion could have been caused by the consumption of cheese in excess, not by the probiotic strain. In the elderly, one-fourth of the participants complained about abdominal pain or bloating, and one-half of the participants reported flatulence throughout the entire trial. Because abdominal pain (12.5\%), bloating
(41.6\%), and flatulence (63.3\%) were also reported during the run-in period, these kinds of complaints seem to be symptoms of an age-related decline in physiological functions. Cheese is rich in saturated fats and proteins and lacks fiber; therefore, excessive consumption of cheese could result in constipation. We found that only the consumption of $100 \mathrm{~g} / \mathrm{d}$ for 3 wk caused hard stools during the second week of the trial.

Lactobacilli could exhibit certain disadvantageous metabolic activities with regard to consumer safety, particularly if BA accumulate in the fermented products (Bernardeau et al., 2008). Biogenic amines have been implicated in several outbreaks of food poisoning and are the initiators of hypertensive crises, hypertension or hypotension, and dietary-induced migraines in certain patients. Nonstarter lactic acid bacteria (including lactobacilli) are associated with cheese-related outbreaks of histamine poisoning (Novella-Rodríguez et al., 2002). Aged cheeses, such as Cheddar, Emmenthaler, and Stilton, typically contain moderate to high concentrations of BA, including tyramine. The amount of clinically significant tyramine per serving is considered $>6 \mathrm{mg}$ (McCabe-Sellers et al., 2006). The cheese used in the present study was Edam-type cheese because this variety is the most common in Estonia and has a ripening period that is relatively short in comparison with other cheese varieties (e.g., Cheddar, Parmesan). Therefore, the possibility of the appearance of very high quantities of BA into this cheese variety is unlikely. However, the incorporation of relatively high viable counts of a human strain of $L$. plantarum into a protein-rich food matrix can trigger unwanted metabolic activity of the strain. Furthermore, L. plantarum has been identified as a producer of BA in Edam-type cheese (Bunková et al., 2010). Therefore, the possible appearance of BA in cheese containing $L$. plantarum Tensia was assessed in the present work. We demonstrated that the strain $L$. plantarum Tensia does not produce potentially harmful BA, such as histamine or cadaverine. The amount of tyramine produced in the cheese during ripening and 15 wk of storage was below the clinically significant content.

Damage to liver function is caused by liver cell damage, resulting in the leakage of enzymes into the blood circulation, indicating injury by various substances, including food. On the other hand, Higashikawa et al. (2010) reported a remarkable improvement in liver function in healthy adults, according to the serum enzymes (including AST and ALT), with intake of cultured yogurt containing a L. plantarum strain, and Ranganathan et al. (2010) reported a lowering of the creatinine level in patients with chronic kidney disease when given a probiotic supplement containing $L$. acidophilus and Bifidobacterium longum. In our trials with 
adult and elderly volunteers, no changes were registered in the values of kidney and liver function markers (serum creatinine, albumin, ALT, and AST) because of probiotic cheese consumption.

No adverse effects on inflammation markers in the blood (WBC count and IgG, IgM, and IgE levels) were detected. In addition, the hs-CRP values were stable in the long-lasting trials. This is a very important finding because C-reactive protein is a marker of inflammation strongly correlated with CVD (Danesh et al., 1998; Moss and Freed, 2003).

Milk fat is considered one of the major sources of dietary cholesterol. The consumption of full-fat varieties of cheese allegedly increases the blood cholesterol level. In our study, the effect of fat on host plasma lipids by participants consuming, for 3 plus $3 \mathrm{wk}$, the semihard Edam-type cheese (fat content 26\%) with and without the probiotic additive was considered negligible. No negative effect on levels of total cholesterol or cholesterol fractions (HDL cholesterol, LDL cholesterol, triglycerides) was observed. Some reports indicate that unlike other full-fat dairy products, such as whole milk or butter, consumption of cheese confers lesser plasma lipid levels, increasing the effect at comparable intakes of total fat and saturated fat (Biong et al., 2004; Tholstrup et al., 2004; Nestel et al., 2005). Some authors suggest that probiotic cultures could beneficially influence the absorption of dietary fat and cholesterol in the small intestine (Agerholm-Larsen et al., 2000; Raff et al., 2008).

Abdominal obesity has been associated with an increased risk of type 2 diabetes, dyslipidemia, hypertension, and especially CVD (de Koning et al., 2007). In contrast, the Hoorn study, with an elderly Dutch population, showed a significant inverse association between consumption of high-fat dairy products and BMI, waist circumference, and blood triglyceride indices and a positive correlation with HDL cholesterol (Snijder et al., 2007). In the present study, no BW gain was detected in the elderly consuming $50 \mathrm{~g}$ of cheese even though they were figured as being a less physically active population subgroup, or in adults consuming 50 or $100 \mathrm{~g}$ of cheese daily for $3 \mathrm{wk}$.

The statistically significant $(P=0.0005)$ decrease in blood serum glucose in adults because of a high dose of cheese consumption is probably because cheese has a low glycemic index but is otherwise a nutrient-dense food that helps postpone the feeling of hunger.

\section{CONCLUSIONS}

The present work demonstrates the safety of consuming a regular semihard Edam-type cheese (fat content of $26 \%$ ) with and without the probiotic additive $L$. plantarum Tensia at a daily dose of $50 \mathrm{~g}$ and in excess $(100 \mathrm{~g})$, and with a daily dose of probiotic of $10 \mathrm{log}$ cfu for $3 \mathrm{wk}$, with no harmful effect on gut health, BMI, inflammatory markers, or serum lipidograms.

\section{ACKNOWLEDGMENTS}

The research was cofinanced by the European Community's Regional Development Fund in the framework of the Competence Centre Programme of the Enterprise Estonia under Project No. EU22868, EU27789, EU28662, EU30002 of the Bio-Competence Centre of Healthy Dairy Products (Tervisliku Piima Biotehnoloogiate Arenduskeskus OÜ, Tartu, Estonia).

\section{REFERENCES}

Adlercreutz, H. 1990. Diet, breast cancer, and sex hormone metabolism. Ann. N. Y. Acad. Sci. 595:281-290.

Agerholm-Larsen, L., M. L. Bell, G. K. Grunwald, and A. Astrup. 2000. The effect of a probiotic milk product on plasma cholesterol: A meta-analysis of short-term intervention studies. Eur. J. Clin. Nutr. 54:856-860.

Annuk, H., J. Shchepetova, T. Kullisaar, E. Songisepp, M. Zilmer, and M. Mikelsaar. 2003. Characterization of intestinal lactobacilli as putative probiotic candidates. J. Appl. Microbiol. 94:403-412.

Bernardeau, M., J. P. Vernoux, S. Henri-Dubernet, and M. Guéguen. 2008. Safety assessment of dairy microorganisms: The Lactobacillus genus. Int. J. Food Microbiol. 126:278-285.

Biong, A. S., H. Müller, I. Seljeflot, M. B. Veierød, and J. I. Pedersen. 2004. A comparison of the effects of cheese and butter on serum lipids, haemostatic variables and homocysteine. Br. J. Nutr. 92:791-797.

Bunková, L., F. Bunka, G. Mantlová, A. Cablová, I. Sedlácek, P. Svec, V. Pachlová, and S. Krácmar. 2010. The effect of ripening and storage conditions on the distributionof tyramine, putrescine and cadaverine in Edam-cheese. Food Microbiol. 27:880-888.

Cannon, J. P., T. A. Lee, J. T. Bolanos, and L. H. Danziger. 2005. Pathogenic relevance of Lactobacillus: A retrospective review of over 200 cases. Eur. J. Clin. Microbiol. Infect. Dis. 24:31-40.

Danesh, J., R. Collins, P. Appleby, and R. Peto. 1998. Association of fibrinogen, C-reactive protein, albumin, or leukocyte count with coronary heart disease: Meta-analyses of prospective studies. JAMA 279:1477-1482.

de Koning, L., A. T. Merchant, J. Pogue, and S. S. Anand. 2007. Waist circumference and waist-to-hip ratio as predictors of cardiovascular events: Meta-regression analysis of prospective studies. Eur. Heart J. 28:850-856.

de Vries, M. C., E. E. Vaughan, M. Kleerebezem, and W. M. de Vos. 2006. Lactobacillus plantarum -Survival, functional and potential probiotic properties in the human intestinal tract. Int. Dairy J. 16:1018-1028.

Djoussé, L., J. S. Pankow, S. C. Hunt, G. Heiss, M. A. Province, E. K. Kabagambe, and R. C. Ellison. 2006. Influence of saturated fat and linolenic acid on the association between intake of dairy products and blood pressure. Hypertension 48:335-341.

EFSA (European Food Safety Authority). 2007. Introduction of a Qualified Presumption of Safety (QPS) approach for assessment of selected microorganisms referred to EFSA. Opinion of the Scientific Committee. EFSA J. 587:1-16.

EFSA (European Food Safety Authority). 2008. Technical guidance prepared by the Panel on Additives and Products or Substances used in Animal Feed (FEEDAP) on the update of the criteria used in the assessment of bacterial resistance to antibiotics of human or veterinary importance. EFSA J. 732:1-15. 
Engberink, M. F., M. A. H. Hendriksen, E. G. Schouten, F. J. A. van Rooij, A. Hofman, J. C. M. Witteman, and J. M. Geleijnse. 2009. Inverse association between dairy intake and hypertension: The Rotterdam Study. Am. J. Clin. Nutr. 89:1877-1883.

FAO/WHO (Food and Agriculture Organization of the United Nations/World Health Organization). 2002. Guidelines for the evaluation of probiotics in food. Food and Agriculture Organization of the United Nations and World Health Organization Working Group Report. Accessed July 20, 2011. http://www.who.int/foodsafety/fs_management/en/probiotic_guidelines.pdf.

Floch, M. H., W. A. Walker, K. Madsen, M. E. Sanders, G. T. Macfarlane, H. J. Flint, L. A. Dieleman, Y. Ringel, S. Guandalini, C. P. Kelly, and L. J. Brandt. 2011. Recommendations for probiotic use-2011 update. J. Clin. Gastroenterol. 45(Suppl.):S168-S171.

Gardiner, G., R. P. Ross, J. K. Collins, G. Fitzgerald, and C. Stanton. 1998. Develpoment of a probiotic cheddar cheese containing human-derived Lactobacillus paracasei strains. Appl. Environ. Microbiol. 64:2192-2199.

Gevers, D., M. Danielsen, G. Huys, and J. Swings. 2003a. Molecular characterization of tet $(\mathrm{M})$ genes in Lactobacillus isolates from different types of fermented dry sausage. Appl. Environ. Microbiol. 69:1270-1275.

Gevers, D., G. Huys, and J. Swings. 2003b. In vitro conjugal transfer of tetracycline resistance from Lactobacillus isolates to other Gram-positive bacteria. FEMS Microbiol. Lett. 225:125-130.

Gomes, A. M. P., F. X. Malcata, F. A. M. Klaver, and H. J. Grande. 1995. Incorporation and survival of Bifidobacterium sp. strain Bo and Lactobacillus acidophilus strain Ki in a cheese product. Neth. Milk Dairy J. 49:71-95.

Goossens, D., D. Jonkers, M. Russel, E. Stobberingh, A. Van Den Bogaard, and R. Stockbrügger. 2003. The effect of Lactobacillus plantarum 299v on the bacterial composition and metabolic activity in faeces of healthy volunteers: A placebo-controlled study on the onset and duration of effects. Aliment. Pharmacol. Ther. 18:495-505.

Hibberd, P. L., and L. E. Davidson. 2008. Safety of probiotics. Agro Food Ind. Hi-Tech. 19:30-33.

Higashikawa, F., M. Noda, T. Awaya, K. Nomura, H. Oku, and M. Sugiyama. 2010. Improvement of constipation and liver function by plant-derived lactic acid bacteria: A double-blind, randomized trial. Nutrition 26:367-374.

Ibrahim, F., S. Ruvio, L. Granlund, S. Salminen, M. Viitanen, and A. C. Ouwehand. 2010. Probiotics and immunosenescence: Cheese as a carrier. FEMS Immunol. Med. Microbiol. 59:53-59.

Klare, I., S. Müller-Bertling, R. Reissbrodt, M. Vancanneyt, J. Swings, H. Goossens, and W. Witte. 2005. Evaluation of new broth media for microdilution antibiotic susceptibility testing of lactobacilli, pediococci, lactococci, and bifidobacteria. Appl. Environ. Microbiol. 71:8982-8986.

Kõll, P., R. Mändar, I. Smidt, P. Hütt, K. Truusalu, R.-H. Mikelsaar, J. Shchepetova, K. Krogh-Andersen, H. Marcotte, L. Hammarström, and M. Mikelsaar. 2010. Screening and evaluation of human intestinal lactobacilli for the development of novel gastrointestinal probiotics. Curr. Microbiol. 61:560-566.

Lévesque, C., L. Piché, C. Larose, and P. H. Roy. 1995. PCR mapping of integrons reveals several novel combinations of resistance genes. Antimicrob. Agents Chemother. 39:185-191.

Levitan, E. B., A. Wolk, and M. A. Mittleman. 2009. Consistency with the DASH diet and incidence of heart failure. Arch. Intern. Med. 169:851-857.

Mathur, S., and R. Singh. 2005. Antibiotic resistance in food lactic acid bacteria-A review. Int. J. Food Microbiol. 105:281-295.

Mayrhofer, S., K. J. Domig, C. Mair, U. Zitz, G. Huys, and W. Kneifel. 2008. Comparison of broth microdilution, E-test, and agar disk diffusion methods for antimicrobial susceptibility testing of Lactobacillus acidophilus group members. Appl. Environ. Microbiol. 74:3745-3748.

McCabe-Sellers, B. J., C. G. Staggs, and M. L. Bogle. 2006. Tyramine in foods and monoamine oxidase inhibitor drugs: A crossroad where medicine, nutrition, pharmacy, and food industry converge. J. Food Compost. Anal. 19(Suppl. 1):S58-S65.
Mercenier, A., I. Lenoir-Wijnkoop, and M. E. Sanders. 2008. Physiological and functional properties of probiotics. Bull. Int. Dairy Fed. 429:2-6.

Mikelsaar, M., H. Annuk, J. Shchepetova, R. Mändar, E. Sepp, and B. Björkstén. 2002. Intestinal lactobacilli of Estonian and Swedish children. Microb. Ecol. Health Dis. 14:75-80.

Mikelsaar, M., J. Stsepetova, P. Hütt, H. Kolk, E. Sepp, K. Lõivukene, K. Zilmer, and M. Zilmer. 2010. Lactobacillus sp. is associated with some cellular and metabolic characteristics of blood in elderly people. Anaerobe 16:240-246.

Moss, M., and D. Freed. 2003. The cow and the coronary: Epidemiology, biochemistry and immunology. Int. J. Cardiol. 87:203-216.

Nakovich, L. 2003. Analysis of biogenic amines by GC/FID and GC/ MS. MS Thesis. Virginia Polytechnic Institute, Blacksburg. Accessed July 20, 2011. http://scholar.lib.vt.edu/theses/available/ etd-09122003-131120/unrestricted/LN_Thesis.pdf.

Nestel, P. J., A. Chronopulos, and M. Cehun. 2005. Dairy fat in cheese raises LDL cholesterol less than that in butter in mildly hypercholesterolaemic subjects. Eur. J. Clin. Nutr. 59:1059-1063.

Nicklas, W., P. Baneux, R. Boot, T. Decelle, A. A. Deeny, M. Fumanelli, and B. Illgen-Wilcke. 2002. Recommendations for the health monitoring of rodent and rabbit colonies in breeding and experimental units: Recommendations of the Federation of European Laboratory Animal Science Associations (FELASA) Working Group on Health Monitoring of Rodent and Rabbit Colonies accepted by the FELASA Board of Management, 9 June 2001. Lab. Anim. 36:20-42.

Novella-Rodríguez, S., M. T. Veciana-Nogués, A. X. Roig-Sagués, A. J. Trujillo-Mesa, and M. C. Vidal-Carou. 2002. Influence of starter and nonstarter on the formation of biogenic amine in goat cheese during ripening. J. Dairy Sci. 85:2471-2478.

OECD (Organisation for Economic Co-operation and Development). 2000. Guidance Document on the Recognition, Assessment, and Use of Clinical Signs as Humane Endpoints for Experimental Animals Used in Safety Evaluation. November 2000. Organisation for Economic Co-operation and Development (OECD) Environmental Health and Safety Publications, Series on Testing and Assessment, No. 19. Accessed May 22, 2012. http://www.oecd. org/officialdocuments/displaydocumentpdf/?cote=ENV/JM/ MONO $(2000) 7 \&$ doclanguage $=e n$.

Raff, M., T. Tholstrup, S. Basu, P. Nonboe, M. Tang Sørensen, and E. M. Straarup. 2008. A diet rich in conjugated linoleic acid and butter increases lipid peroxidation but does not affect atherosclerotic, inflammatory, or diabetic risk markers in healthy young men. J. Nutr. 138:509-514.

Ranganathan, N., P. Ranganathan, E. A. Friedman, B. Joseph A. Delano, D. S. Goldfarb, P. Tam, A. V. Rao, E. Anteyi, and C. G. Musso. 2010. Pilot study of probiotic dietary supplementation for promoting healthy kidney function in patients with chronic kidney disease. Adv. Ther. 27:634-647.

Reid, G. 2005. The importance of guidelines in the development and application of probiotics. Curr. Pharm. Des. 11:11-16.

Rijkers, G.T., S. Bengmark, P. Enck, D. Haller, U. Herz, M. Kalliomaki, S. Kudo, I. Lenoir-Wijnkoop, A. Mercenier, E. Myllyluoma, S. Rabot, J. Rafter, H. Szajewska, B. Watzl, J. Wells, D. Wolvers, and J.-M. Antoine. 2010. Guidance for substantiating the evidence for beneficial effects of probiotics: Current status and recommendations for future research. J. Nutr. 140(3S):671S-676S.

Ross, R., G. Fitzgerald, J. K. Collins, G. C. Sullivan, and C. Stanton. 2005. Process of manufacture of probiotic cheese. Enterprise Ireland and Teagasc, The Agriculture and Food Development Authority, Assignee. US Pat. No. 6872411. Accessed July 20, 2011. http://www.freepatentsonline.com/6872411.html.

Saarela, M., G. Morgensen, R. Fondén, J. Mättö, and T. MattilaSandholm. 2000. Probiotic bacteria: Safety, functional and technological properties. J. Biotechnol. 84:197-215.

Salminen, M. K., H. Rautelin, S. Tynkkynen, T. Poussa, M. Saxelin, V. Valtonen, and A. Jarvinen. 2004. Lactobacillus bacteremia, clinical significance, and patient outcome, with special focus on probiotic L. rhamnosus GG. Clin. Infect. Dis. 38:62-69. 
Sepp, E., M. Mikelsaar, and S. Salminen. 1993. Effect of administration of Lactobacillus casei strain GG on the gastrointestinal microbiota of newborns. Microb. Ecol. Health Dis. 6:309-314.

Snijder, M. B., A. A. W. A. van der Heijden, R. M. van Dam, C. D. A Stehouwer, G. J. Hiddink, G. Nijpels, R. J. Heine, L. M. Bouter, and J. M. Dekker. 2007. Is higher dairy consumption associated with lower body weight and fewer metabolic disturbances? The Hoorn Study. Am. J. Clin. Nutr. 85:989-995.

Songisepp, E., T. Kullisaar, P. Hütt, P. Elias, T. Brilene, M. Zilmer, and M. Mikelsaar. 2004. A new probiotic cheese with antioxidative and antimicrobial activity. J. Dairy Sci. 87:2017-2023.

Songisepp, E., Mikelsaar, M., Rätsep, M., Zilmer, M., Hütt, P., Utt, M., Zilmer, K., Üksti, J., Kõljalg S. 2009. Isolated microorganism strain Lactobacillus plantarum Tensia DSM 21380 as antimicrobial and antihypertensive probiotic, food product and composition comprising said microorganism and use of said microorganism for preparation of antihypertensive medicine and method for suppressing pathogens and nonstarter lactobacilli in food product. BioCompetence Centre of Healthy Dairy Products LLC, assignee. Pat Appl. No. WO2009138091.

Štšepetova, J., E. Sepp, H. Kolk, K. Lõivukene, E. Songisepp, and M. Mikelsaar. 2011. Diversity and metabolic impact of intestinal Lactobacillus species in healthy adults and the elderly. Br. J. Nutr. 105:1235-1244.

Svedlund, J., I. Sjodin, and G. Dotevall. 1988. GSRS-A clinical rating scale for gastrointestinal symptoms in patients with irritable bowel syndrome and peptic ulcer disease. Dig. Dis. Sci. 33:129-134.

Tannock, G. W., J. B. Luchansky, L. Miller, H. Connell, S. ThodeAndersen, A. A. Mercer, and T. R. Klaenhammer. 1994. Molecular characterization of a plasmid-borne (pGT633) erythromycin resistance determinant (ermGT) from Lactobacillus reuteri 100-63. Plasmid 31:60-71.

Tholstrup, T., C.-E. Høy, L. N. Andersen, R. D. K. Christensen, and B. Sandström. 2004. Does fat in milk, butter and cheese affect blood lipids and cholesterol differently? J. Am. Coll. Nutr. 23:169-176.

Toledo, E., M. Delgado-Rodríguez, R. Estruch, J. Salas-Salvadó, D Corella, E. Gomez-Gracia, M. Fiol, R. M. Lamuela-Raventós, H. Schröder, F. Arós, E. Ros, V. Ruíz-Gutiérrez, J. Lapetra, M. Conde-Herrera, G. Sáez, E. Vinyoles, and M. A. MartínezGonzález. 2009. Low-fat dairy products and blood pressure: Follow-up of 2290 older persons at high cardiovascular risk participating in the PREDIMED study. Br. J. Nutr. 101:59-67.

Truusalu, K., P. Naaber, T. Kullisaar, H. Tamm, R. Mikelsaar, K. Zilmer, A. Rehema, M. Zilmer, and M. Mikelsaar. 2004. The influence of antibacterial and antioxidative probiotic lactobacilli on gut mucosa in a mouse model of Salmonella infection. Microb. Ecol. Health Dis. 16:180-187.

Vankerckhoven, V., G. Huys, M. Vancanneyt, C. Vael, I. Klare, M.-B. Romond, J. M. Entenza, P. Moreillon, R. D. Wind, J. Knol, E. Wiertz, and B. Pot. 2008. Biosafety assessment of probiotics used for human consumption: Recommendations from the EU-PROSAFE project. Trends Food Sci. Technol. 19:102-114.

Vesterlund, S., V. Vankerckhoven, M. Saxelin, H. Goossens, S. Salminen, and A. C. Ouwehand. 2007. Safety assessment of Lactobacillus strains: Presence of putative risk factors in faecal, blood and probiotic isolates. Int. J. Food Microbiol. 116:325-331.

Wind, R. D., H. Tolboom, I. Klare, G. Huys, and J. Knol. 2010. Tolerance and safety of the potentially probiotic strain Lactobacillus rhamnosus PRSF-L477: A randomised, double-blind placebo-controlled trial in healthy volunteers. Br. J. Nutr. 104:1806-1816. 